the variegated plants bore light pink flowers somewhat lighter and more delicate in color than the ordinary red flowers of the green plants. This instance, typical of many others observed by the writer in southern California, illustrates the origin of the variegated forms of the oleander and their propagation from bud variations.

In the catalogue of one of the leading ornamental tree growers of California, seventeen commercial varieties of the oleander are offered for sale. The foliage characteristics of these varieties include green and variegated leaves. Some of the varieties are distinguished by different degrees or arrangement of the variegations. The flower characteristics of the different varieties include white-single, doublewhite, semi-double white or pink, variegated flowers, carmine-crimson and shaded maroon colors, fragrance or the absence of fragrance, carmine streaked with white color and the production of many or of few flowers. Some, if not all, of these varieties, have been isolated through the selection and propagation of bud sports. In several instances the writer has observed some of these bud variations occurring on the same plant, frequently as branch sports. An inquiry amongst local propagators has revealed the fact that the different varieties listed above have been propagated from bud sports, usually from bud variations of the variegated plants. In one instance a row of variegated plants having both striped leaves and flowers was propagated from cuttings said to have been secured from variegated branches occurring as bud variations in a green leaf and red-flowered plant. However, in most cases the varieties have most frequently developed apparently as selections from bud variations of the variegated plants.

\title{
PUREBRED SIRES LEAD RAPIDLY TO IMPROVEMENT IN FEMALE STOCK
}

\section{Current Results in Federal-State Campaign for Better-Bred Livestock Furnish Striking Facts About Breeding}

\author{
D. S. BurCH
}

\section{Bureau of Animal Industry, U. S. Department of Agriculture}

$\mathrm{T}$ WHAT the use of good purebred sires generally is a forerunner to ownership of well-bred livestock in the various classes and breeds is shown by data assembled by the Bureau of Animal Industry, U. S. Department of Agriculture. The facts and figures compiled are derived from records of the "Better Sires-Better Stock" campaign which, at the close of 1920 , had been in progress 15 months. It is a campaign of information with the object of improving the average quality of live stock in the United States. The following facts are believed to be of unusual interest to livestock owners and students of animal breeding:

\section{OWNERSHIP OF PUREBRED FEMALES FOLLOWS BETTER SIRES}

The use of purebred sires appears to lead automatically to the ownership of a considerable quantity of purebred female stock. The proportion of purebred female animals kept in herds and flocks headed by purebred sires is gradually increasing.

The use of purebred sires apparently results also in the culling out of scrub females, judging from the small proportion of scrub females compared with grade, crossbred, and purebred female animals owned by purebred-sire users.

Of all female stock owned by persons enrolled in the "Better-Sires" campaign at the end of $1920,55.9$ per cent were purebreds, 33.4 per cent were grades; 8.6 per cent were crossbreds, and 2.1 per cent were scrubs. In about a year's time, it appears, the increase in the use of purebred females by purebred-sire owners has been at least 7 per cent.

In the opinion of Department livestock specialists, the more general use 


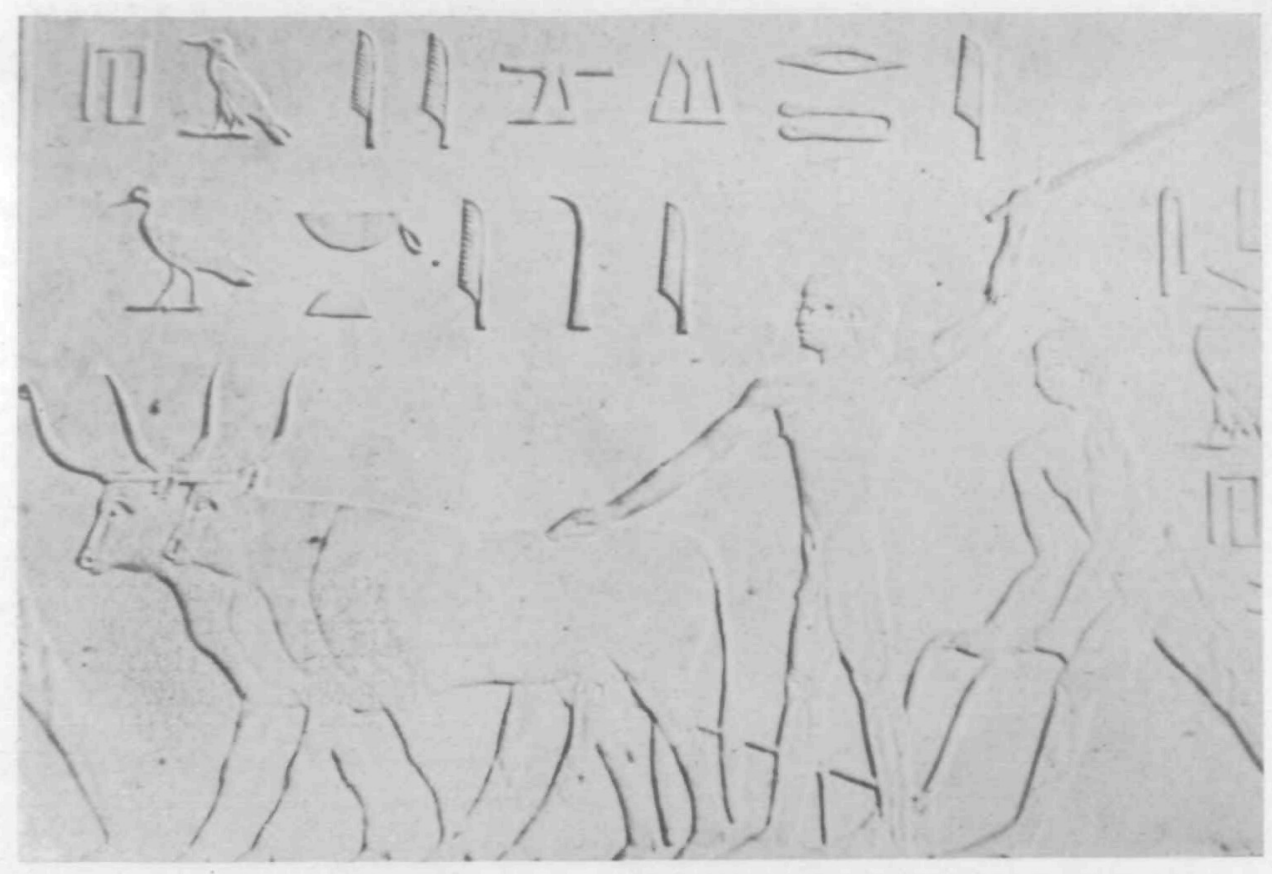

\section{EGYPTIAN CATTLE OF CENTURIES AGO}

This picture, from a tomb relief of the 26th Century B. C., shows Egyptian peasants plowing. It is interesting in this connection because it shows the type of cattle which evidently existed at that time. Those depicted here were undoubtedly well fitted for draught purposes, but very far from the type desired for beef purposes. The sway back, thin body and long legs are what breeders throughout the centuries have sought to overcome. (Photograph by courtesy of National Museum.) (Fig. 32.)

of purebreds on farms in the United States is increasing.

The scrub females are believed to be the remnants of former inferior stock before purebred sires were used, since purebred males lead automatically to either purebred, crossbred, or grade offspring, depending on the bloodlines of the females used.

It is noteworthy that the largest proportion of female stock of pure breeding occurs in the case of the smaller and more prolific animals. In poultry the proportion of purebred females to all females was 70.5 per cent, and in swine 65.4 per cent. The corresponding figure for cattle was 37 per cent, and for horses 11.9.

Comments accompanying blanks of enrollment indicated that many livestock owners had used purebred sires for a considerable period, which explains the low percentage of scrubs.
This evidence points strongly to the influence of purebred sires on improvement in quality of herds and flocks.

\section{SHOWS RESULTS OF STATE WORK FOR BETTER BULLS}

The drive which many States have been waging against scrub bulls was reflected in the figures of the Department. More purebred bulls were enrolled in the "Better-Sires" movement than any other sires except poultry. At the end of December, 1920, there were enrolled in the "Better-SiresBetter Stock" campaign 156,832 animals, and, in addition, 238,122 poultry.

\section{RATIO OF SIRES TO DAMS}

Developments of the campaign have resulted also in figures showing the relative number of males and females kept on farms for breeding purposes. Following are the ratios based on nearly 


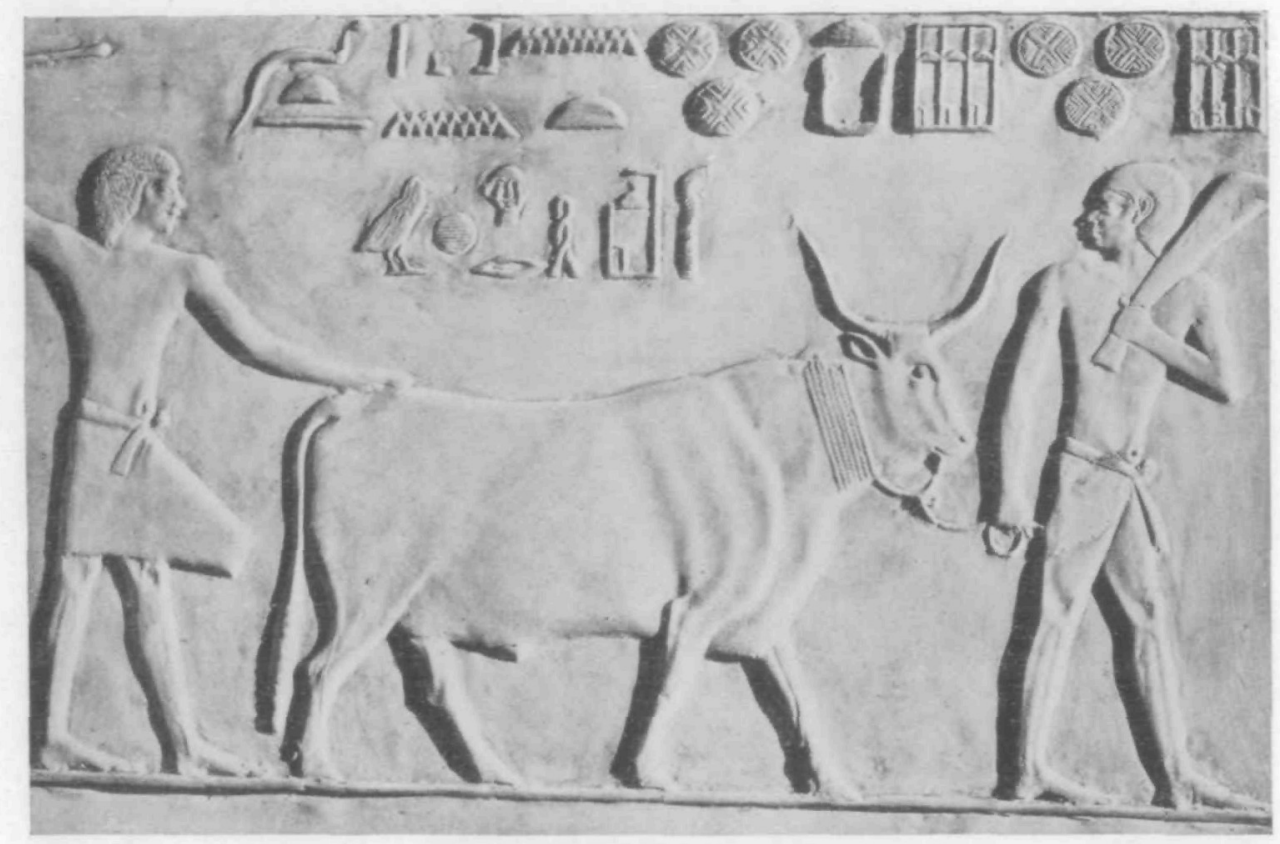

\section{ANOTHER TYPE OF EARLY EGYPTIAN CATTLE}

According to ancient carvings, this is one kind of cattle raised in Egypt centuries ago. Note the depth of body and blocky conformation of this animal, in contrast to those on the opposite page. This one shows several characteristics desired by modern breeders. Evidently it was the Egyptians' beef type of cattle, and this one is shown being led to slaughter. (Photograph by courtesy of National Museum.) (Fig. 33.)

400,000 head of livestock and poultry listed with the Department:

Cattle.....1 bull to 17.5 cows.

Horses... . 1 stallion to 17.2 mares.

Swine....1 boar to 11.1 sows.

Sheep. ....1 ram to 32.3 ewes.

Goats... . . 1 buck to 23.9 does.

Fowls. . . . 1 rooster to 23.9 hens.

Other poultry,

geese, ducks,

turkeys, etc.

(average)..1 male to 10.6 females.

FACTS OBTAINED WITH SPECIAL CARE

Knowledge of the breeding of livestock in the "Better Sires-Better Stock" campaign is obtained with special care. First, the owner of the stock lists his animals kept for breeding on the enrollment blank in accordance with the official definitions for the various classes of animals with respect to their parentage. As the better-sires slogan indicates, all males must be purebred and of good quality.

Female stock may be of any breed- ing and spaces are provided for the listing of purebred, grade, crossbred, and scrub females. Then the classification is approved by the county agent in the county where the livestock owner lives. In the relatively few cases where there is no county agent, the written indorsement of the blank by two experienced and disinterested livestock owners is required.

Every person agreeing in writing, on the blank furnished, to use only purebred sires in his breeding operations receives an emblem of recognition issued cooperatively by the United States Department of Agriculture and the State in which he lives. So-called "red tape" has been reduced to a minimum and the emblems have been issued in most cases the day the blanks were received.

\section{FEMALE STOCK NEED NOT BE PURE- BRED}

Though pointing out the foregoing observations-and especially the ten- 


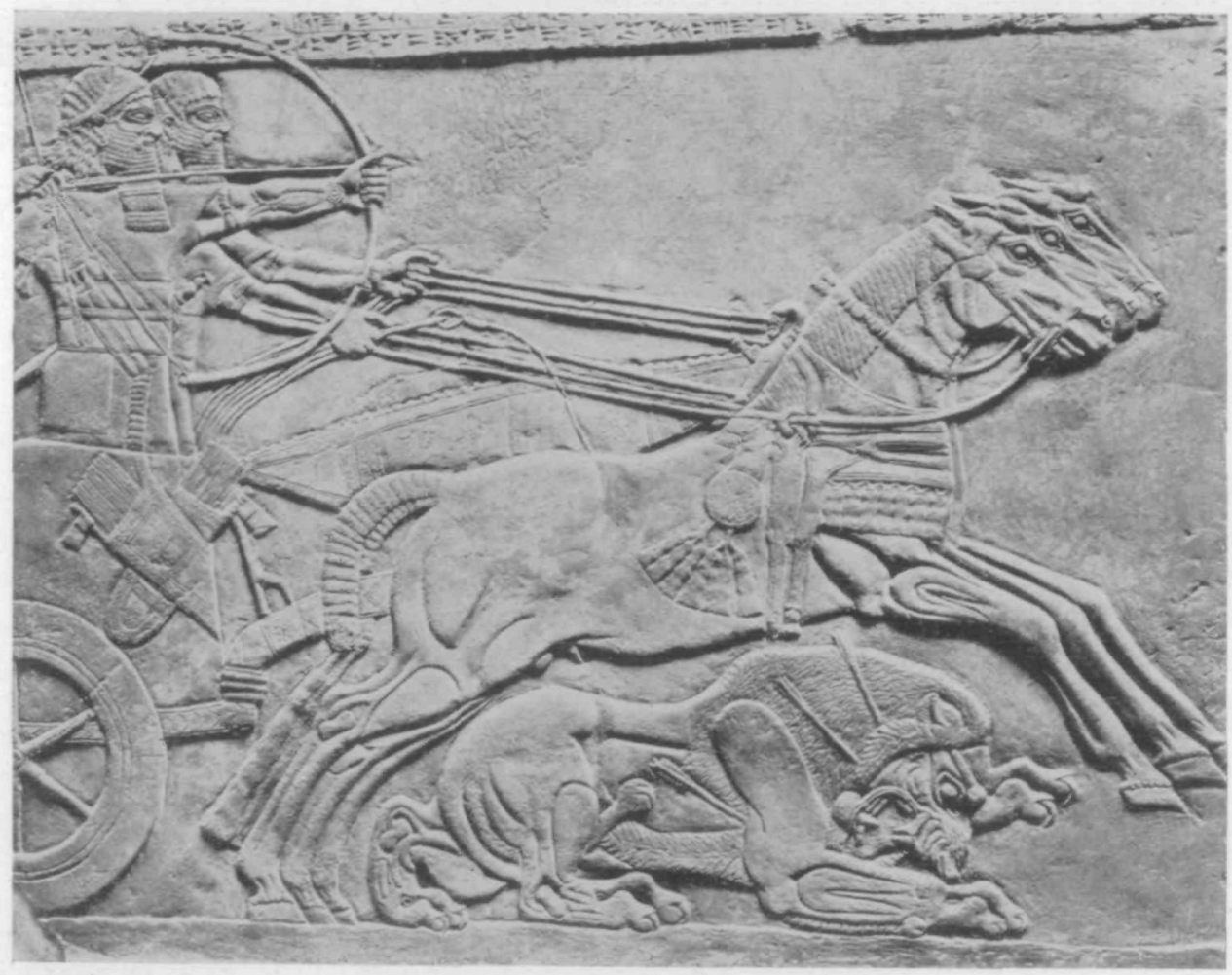

\section{ASSYRIAN HORSES IN ACTION}

This picture is from a marble slab carved more than six centuries before the Christian Era The horses of that time, according to the carving, were of a better type than many of the scrub and grade horses now used by farmers in the United States. (Courtesy of National Museum.) (Fig. 34.)

dency for purebred-sire owners to acquire purebred females-the Department of Agriculture does not urge purebred female stock on the average farm. Whether purebred females should be kept is a matter of individual judgment, depending on circumstances which the livestock owner is best able to know. The successful breeding of purebred livestock as a business calls for close attention and considerable experience, both in production and marketing. By contrast, the purpose of the better-sires movement is to raise the average quality of all livestock in the United States.

The Department therefore goes no further than to urge the use of good purebred sires. It believes that after having taken that step livestock owners will continue to improve their domestic animals, raising either grades, crossbreds, or purebreds-or some of eachwhichever seems best suited to the kind of farming followed, and to available markets.

In connection with the foregoing recommendation the Department points out that the breeding of good livestock is by no means a new industry. Ancient carvings show classes of domestic animals which appear to have been very creditable, and, judging from obtainable evidence, some of the animals centuries ago were of better type than the more inferior animals in the United States today. This fact points out the need for continued study and the use of good breeding stock. Economic conditions of today require the most efficient live-stock we can produce. 